\title{
RESPON PERTUMBUHAN JAGUNG TERHADAP PEMBERIAN PUPUK- PUPUK NPK, UREA, SP-36, DAN KCL
}

\section{MAIZE GROWTH RESPONSE TO THE PROVISION OF NPK, UREA, SP-36, AND KCL FERTILIZERS}

\author{
Tilda Titah dan Joko Purbopuspito ${ }^{1)}{ }^{*}$ ) \\ 1)Fakultas Pertanian Unsrat Manado \\ *) Penulis korespondensi: joko.purbopuspito@unsrat.ac.id
}

\begin{abstract}
Potted trial for understanding Maize (Zea mays, L.) growth responses on the given dosage of $100 \mathrm{~kg}$ $\mathrm{N} / \mathrm{ha}$ of NPK and Urea, $100 \mathrm{~kg} \mathrm{P} / \mathrm{ha}$ of SP-36, and $100 \mathrm{~kg} \mathrm{K/ha} \mathrm{KCl} \mathrm{fertilizers} \mathrm{growing} \mathrm{on} \mathrm{Latosol}$ Kalasey was conducted in six replicates until the plants reaching 8 weeks old at the backyard of Soil Department building. Plant height and number of mature leaves increased significantly with age of Maize plants, but the plant responses on given fertilizers did not significantly different. Fresh weight dan oven-dry weight of Maize stalk did also show similar trend due to given fertilizers; however, application of singular fertilizers, such as: Urea, SP-36 and $\mathrm{KCl}$ gave relatively higher results in contrast to the compound NPK fertilizer. Urea tend to increase succulence of Maize plants.
\end{abstract}

Keywords: maize, growth response, NPK, Urea, SP-36, KCl, fertilizers

\begin{abstract}
ABSTRAK
Percobaan pot untuk mengetahui respon pertumbuhan jagung (Zea mays, L.) terhadap pemberian pupuk-pupuk NPK, Urea, SP-36, dan KCl pada Latosol Kalasey dengan dosis $100 \mathrm{~kg} \mathrm{~N} / \mathrm{ha}, 100 \mathrm{~kg}$ P/ha dan $100 \mathrm{~kg} \mathrm{~K} / \mathrm{ha}$ dikerjakan dalam enam ulangan hingga tanaman berumur 8 MST di belakang gedung Jurusan Tanah. Tinggi tanaman dan jumlah daun jagung meningkat secara signifikan seiring umur tanaman, tetapi respon tanaman akibat perlakuan jenis pupuk yang diberikan tidak signifikan berbeda. Berat basah dan berat kering tajuk jagung juga menunjukkan kecenderungan yang sama dalam responnya terhadap jenis pupuk yang diberikan, tetapi perlakuan pupuk tunggal $\mathrm{N}, \mathrm{P}$ dan $\mathrm{K}$ memberikan berat basah dan berat kering tajuk yang relatif lebih tinggi dari perlakuan pupuk lengkap NPK. Pupuk $\mathrm{N}$ cenderung memberikan pengaruh sukulensi pada tanaman jagung. Penggunaan dosis pupuk yang lebih besar disarankan untuk penelitian respon tanaman selanjutnya.

Kata kunci: jagung, respons tumbuh, pupuk, NPK, Urea, SP-36, KCI
\end{abstract}

Eugenia Volume 22 No. 2 Juni 2016 


\section{PENDAHULUAN}

Jagung (Zea mays, L.) merupakan salah satu bahan makanan sumber minyak nabati yang potensial. Pertumbuhan jagung dipengaruhi oleh faktor internal tanaman: genetik, enzim dan hormon; dan faktor eksternal: cahaya, suhu, kelembaban dan ketersediaan air, oksigen, dan nutrisi/zat hara tanah untuk tanaman. Penambahan zat hara pada tanah dapat mempengaruhi pertumbuhan tanamanjagung.

Tanah merupakan tubuh alam pada sebagian besar permukaan bumi yang menumbuhkan tanaman dan memiliki sifat tanah yang khas akibat pengaruh iklim dan jasad hidup terhadap bahan induk berrelief tertentu selama jangka waktu perkembangannya. Kesuburan tanah adalah suatu keadaan tanah dimana tata air, udara dan unsur hara dalam keadaan cukup seimbang dan tersedia sesuai kebutuhan tanaman, baik fisik, kimia dan biologi tanah (Effendi, 1995). Tanah sebagai media tanam berfungsi sebagai pemasok, pencadang dan penyedia unsur hara tanaman, dengan keragaman kualitas media tumbuh tanaman. Jagung memerlukan hara tanaman (plant nutrient) untuk memenuhi siklus hidupnya. Apabila suatu tanaman kekurangan suatu unsur hara, maka akan menampakkan gejala tertentu yang spesifik dan biasa disebut gejala kekahatan (gejala defisiensi). Unsur hara yang diperlukan tanaman tidak seluruhnya dapat dipenuhi dari tanah, sehingga perlu penambahan dari luar yang berbentuk pupuk dan digunakan untuk mendorong pertumbuhan dalam pembentukan daun, akar, batang serta dalam pembentukan polong (biji). Penelitian ini bertujuan mengukur respon tanaman jagungterhadap pengaruh pupuk/ pemupukan, dan mengetahui perbandingan respon tumbuh antar perlakuan.

\section{METODE PENELITIAN}

Pengambilan contoh tanah untuk penelitian ini dilaksanakan pada hari Sabtu, 21 Februari 2015 pada Latosol Kalasey (Gambar Lampiran 1), dan percobaan pot dengan berat tanah kering udara sebanyak $4 \mathrm{~kg}$ dalam tiga ulangan dimulai pada hari Jumat 27 Februari 2015 hingga 27 April 2015 berlokasi di belakang gedung Jurusan Tanah Fakultas Pertanian UNSRAT dengan penimbangan berat kering tanaman di Laboratorium Kesuburan Tanah.

Dosis-dosis pupuk NPK, N, P, dan K, ditimbang sesuai takaran yang ditentukan, yakni: 100 $\mathrm{kg} \mathrm{N} / \mathrm{ha}$, yang setara dengan $1,33 \mathrm{~g} \mathrm{NPK} /$ pot dan0,44 g Urea/pot, $100 \mathrm{~kg} \mathrm{P/ha} \mathrm{dan} 100 \mathrm{~kg} \mathrm{K/ha,}$ yang setara dengan $1,22 \mathrm{~g} \mathrm{SP}-36 /$ pot dan $0,48 \mathrm{~g}$ $\mathrm{KCl} /$ pot. Dengan alat yang tersedia (pacul, sekop, karung, ember, timbangan), tanah diambil dari lapangan, dikering-anginkan dan dihancurkan serta ditimbang sebanyak $4 \mathrm{~kg}$ per pot dan dimasukkan ke pot yang berupa ember. Benih jagung sebanyak 5 biji per pot ditanam berkluster segi-lima dengan kedalaman $2 \mathrm{~cm}$ dari permukaan tanah dalam pot. Bibit yang tumbuh kemudian dijarangkan hanya mensisakan 2 tanaman terbaik per pot, yang kemudian diamati dan dicatat pertumbuhan tinggi tanaman dan jumlah daunnya, setiap minggu hingga panen pada minggu ke 8 sebelum masa generatif tanaman dimulai. Selama masa pertumbuhan, potpot percobaan disiram dengan air secukupnya agar tanaman dapat tumbuh dengan baik dan dijaga dari serangan hama dan penyakit. Pada akhir minggu ke 8 (24 April 2015), tanaman dipanen, ditimbang dan dicatat berat basahnya lalu dikeringkan dalam oven pada suhu $70^{\circ} \mathrm{C}$ selama tiga hari dan ditimbang serta dicatat kembali berat keringnya.

Setelah data pertumbuhan tanaman terkumpul, analisis statistik (Anova faktor tunggal perlakuan pupuk) dan grafik sederhana dikerjakan untuk melihat pengaruh pupuk dan respon tanaman terhadap berbagai jenis pupuk NPK, Urea, SP-36, dan $\mathrm{KCl}$ yang diberikan.

\section{HASIL DAN PEMBAHASAN}

Tinggi tanaman jagung (Zea mays, L.) bertambah secara nyata dan signifikan dengan waktu pengamatan untuk semua perlakuan pupuk, dengan nilai- $P=0,000$, F-hitung $=10,919>F-k r i t e r i a=$ 2,209 (Gambar 1, Gambar Lampiran 2). 

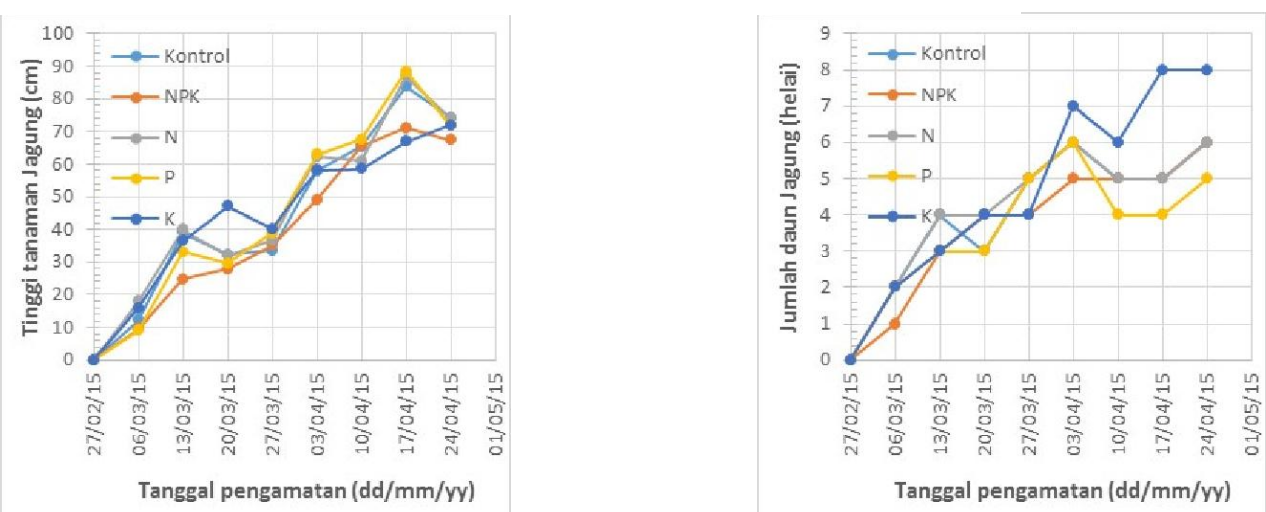

Gambar 1. Tinggi Rata-rata Tanaman Jagung (Zea mays, L.) pada Setiap Waktu Pengamatan

(Figure 1. Average Maize (Zea mays, L.) Plant-height on the Date of Observations)

Tabel 1. Rata-rata Tinggi $(\mathrm{cm})$ Tanaman Jagung dan Nilai Uji Beda Statistiknya pada Setiap Waktu Pengamatan

(Table 1. Average Maize (Zea mays, L.) Plant-height and its Statistical Tests on the Date of Observations)

\begin{tabular}{crrrrrrrrc}
\hline \multirow{2}{*}{$\begin{array}{c}\text { Tanggal } \\
\text { pengamatan }\end{array}$} & \multicolumn{4}{c}{$\begin{array}{c}\text { Respon tinggi tanaman jagung rata-rata }(\mathrm{cm}) \\
\text { pada perlakuan pupuk }\end{array}$} & \multicolumn{4}{c}{ Uji beda statistik } \\
\cline { 2 - 10 } & Tanpa & NPK & $\mathrm{N}$ & $\mathrm{P}$ & $\mathrm{K}$ & nilai P & F-hit. & F-krit. & notasi \\
\hline $06 / 03 / 2015$ & 12,2 & 9,4 & 18,0 & 9,0 & 15,8 & 0,681 & 0,605 & 6,388 & tn \\
$13 / 03 / 2015$ & 39,0 & 24,7 & 40,0 & 33,1 & 36,5 & 0,458 & 1,072 & 5,192 & tn \\
$20 / 03 / 2015$ & 32,2 & 27,8 & 32,1 & 29,6 & 47,0 & 0,811 & 0,392 & 2,895 & tn \\
$27 / 03 / 2015$ & 33,6 & 35,1 & 36,7 & 38,8 & 40,2 & 0,976 & 0,113 & 2,895 & tn \\
$03 / 04 / 2015$ & 57,8 & 49,1 & 62,2 & 63,0 & 58,0 & 0,642 & 0,638 & 2,895 & tn \\
$10 / 04 / 2015$ & 65,3 & 65,7 & 61,0 & 67,5 & 58,5 & 0,994 & 0,055 & 3,056 & tn \\
$17 / 04 / 2015$ & 83,8 & 71,1 & 86,8 & 88,3 & 67,0 & 0,545 & 0,809 & 3,357 & tn \\
$24 / 04 / 2015$ & 74,2 & 67,4 & 74,0 & 71,7 & 72,0 & 0,995 & 0,049 & 2,895 & tn \\
\hline
\end{tabular}

tn= tidak berbeda nyata

Uji beda statistik respon tinggi tanaman jagung terhadap perlakuan pupuk (Tabel 1) pada setiap minggu pengamatan menunjukkan bahwa respon tinggi tanaman jagung tidak signifikan berbeda terhadap perlakuan pupuk yang berbeda. Kurva tinggi tanaman jagung rata-rata yang dipupuk NPK (Gambar 1 dan Tabel 1) cenderung lebih rendah dari tinggi tanaman jagung yang dipupuk Urea maupun SP-36. Sedangkan kurva pertumbuhan tanaman jagungyang dipupuk $\mathrm{K}$ pada minggu awal pertumbuhan lebih tinggi dari tanaman yang dipupuk NPK, tetapi pada minggu-minggu terakhir pertumbuhan sebelum tanaman dipanen menjadi lebih rendah dari tinggi tanaman yang diberi pupuk NPK. Pengaruh pupuk K terhadap tanaman umumnya cenderung membuat tanaman lebih cepat bertambah tinggi (Rahayu, 2012; Tarigan, 2010). Fungsi unsur hara $\mathrm{K}$ secara umum adalah meningkatkan pertumbuhan jaringan meristem, mem- perkuat tegaknya batang dan membantu perkembangan akar tanaman (Rahayu, 2012; Karmana, 2006). Selain pemupukan, pemberian air juga penting bagi tanaman guna melakukan proses-proses metabolismenya yaitu: transport senyawa, mempertahankan turgor sel, menjaga suhu dan proses fotosintesis (Nidayani, 2014; Jozckam, 2010; dan Puryana, 2008). Pemberian air yang berlebihan, baik yang disebabkan oleh penyiraman maupun yang disebabkan oleh hujan menurut Nidayani (2014); Hayati (2011) dan Karmana (2006) dapat menyebabkan tanaman tergenang dan layu sehingga pertumbuhannya terhambat, terlebih lagi pot percobaan yang dipakai dalam penelitian ini tidak berlubang drainase untuk pembuangan kelebihan air. Joseph (2011) juga berpendapat bahwa peranan pupuk majemuk NPK membuat vigor tanaman jadi kekar dan seimbang tegaknnya karena unsur hara tanaman yang relatif lengkap dibandingkan 
pupuk tunggal, sehingga batang tubuh jagung yang dipupuk dengan pupuk majemuk NPK lebih rendah dibanding dengan yang dipupuk Urea ataupun $\mathrm{KCl}$.

Kurva pertambahan jumlah daun tanaman jagung rata-rata yang dipupuk SP-36 (Gambar 1 dan Tabel Lampiran 1) cenderung lebih rendah dari kurva pertambahan jumlah daun tanaman jagung yang dipupuk $\mathrm{KCl}$ maupun Urea dan kurva pertambahan jumlah daun tanaman jagung yang dipupuk NPK relatif sama dengan jumlah daun yang tanpa pemberian pupuk. Joseph (2011) dan Juliantoro (2011) berpendapat pengaruh pupuk majemuk NPK juga memberikan tingkat efisiensi fotosintesisyang lebih baik sehingga dengan jumlah daun yang sedikit mampu menyerap energi matahari yang tersedia. Dalam penelitian ini, daun jagung yang dipupuk NPK dan P tampak berwarna hijau lebih gelap dibandingkan daun jagung yang diberi pupuk Urea maupun $\mathrm{KCl}$ saja yang berwarna hijau cerah.

Rata-rata berat basah dan berat kering tajuk jagung (Zea mays, L.) berumur 8 MST (Gambar 2 dan Tabel Lampiran 2) memperlihatkan bahwa tanaman jagung yang diberi pupuk Urea memiliki berat tajuk relatif tinggi dibandingkan perlakuan lainnya, yang juga mengindikasikan bahwa tanah Latosol Kalasey mempunyai kekahatan nitrogen. Nitrogen dalam tanah dicirikan mirip dengan karbon, yakni warna tanah yang gelap. Hasil pengamatan warna tanah sewaktu pengambilan contoh tanah, menunjukkan warna yang coklat tetapi tidak gelap (Gambar Lampiran 1). Gumeleng (2003) memaparkan fungsi nitrogen (N)

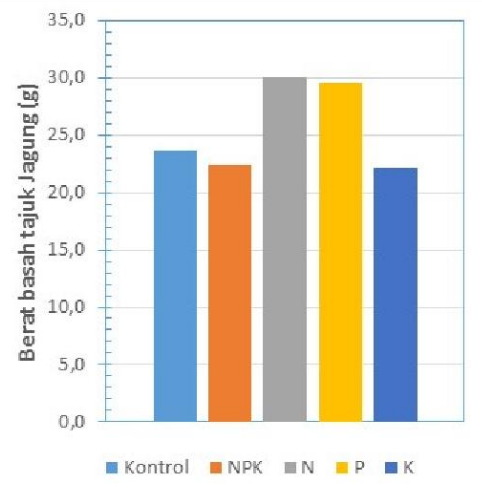

bagi tanaman adalah mempercepat pertumbuhan tanaman, menambah tinggi tanaman, dan merangsang pertunasan yang bersesuaian dengan hasil penelitan ini yang menunjukkan respon tinggi tanaman dan berat tajuk tanaman jagung terhadap pupuk Urea relatif lebih besar dibandingkan respon tanaman terhadap pupuk lainnya (Gambar 1 dan 2).

Perbandingan rata-rata berat kering $(\mathrm{g})$ tajuk jagung (Zea mays, L.) Purbopuspito, dkk. 2015; kacang merah (Phaseolus vulgaris, L.) Rondonuwu, dkk. 2015; dan kacang tanah (Arachis hypogaea, L.) Kawulusan, dkk. 2015, berumur 8 MST (Gambar 3), menunjukkan tanaman yang berbeda jenisnya memiliki respon-respon yang relatif sama terhadap pemberian pupuk tunggal Urea, SP36 dan $\mathrm{KCl}$ maupun pupuk majemuk NPK. Tanaman jagung terlihat sangat responsif dibandingkan kacang merah maupun kacang tanah (Gambar 3) terhadap perlakuan pupuk-pupuk yang diberikan. Tanaman jagung dan kacang merah juga sangat responsif terhadap pemupukan Urea dibandingkan tanaman kacang tanah.

Unsur hara $\mathrm{P}$ diperlukan tanaman dalam jumlah lebih sedikit daripada unsur hara N. Walaupun unsur hara $\mathrm{P}$ sangat penting bagi tanaman, karena berperan dalam proses perkembangan akar sehingga meningkatkan daya tahan tanaman terhadap kekeringan dan mempercepat pemasakan buah serta mengurangi resiko keterlambatan panen (Sutejo, 2002), tetapi ketersediaan $P$ dari pupuk SP-36 dalam tanah sangat lambat, terlebih lagi pada tanah Latosol yang secara alami memang mempunyai kadar P-tersedia dari tanah yang rendah.

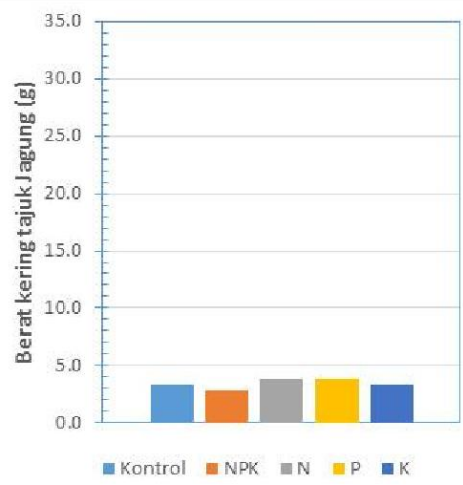

Gambar 2. Rata-rata Berat Basah (g) dan Berat Kering (g) Tajuk Jagung (Zea mays, L.) Berumur 8 MST (Figure 2. Fresh Weight (g) and Dry Weight (g) of 8 WAP Maize (Zea mays, L.) Stalk Averages) 

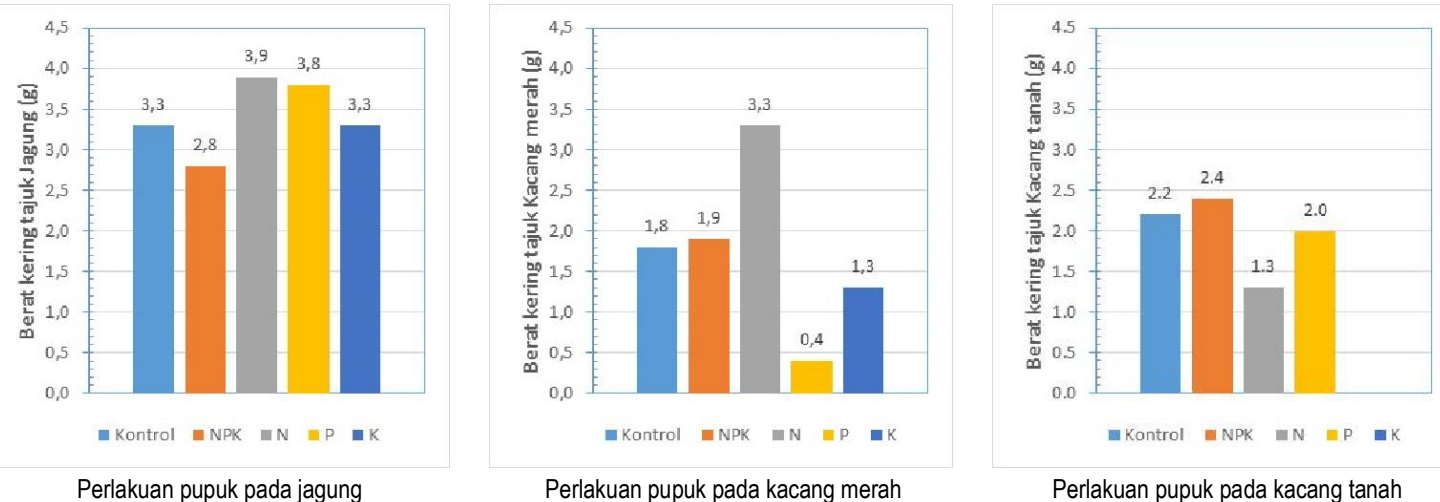

Gambar 3. Perbandingan rata-rata berat kering (g) tajuk jagung (Zea mays, L.; Purbopuspito dkk. 2015), Kacang Merah (Phaseolus vulgaris, L.; Rondonuwu, dkk. 2015), dan Kacang tanah (Arachis hypogaea, L.; Kawulusan, dkk. 2015) berumur 8 MST.

(Figure 3. Comparison of 8 WAP dry-weight average (g) of Maize (Zea mays, L.; Purbopuspito dkk. 2015), Red bean (Phaseolus vulgaris, L.; Rondonuwu, dkk. 2015), and Peanut (Arachis hypogaea, L.; Kawulusan, dkk. 2015).)

Tanaman kacang merah dan kacang tanah adalah jenis-jenis leguminosa yang mampu menambat $\mathrm{N}$ dari udara melalui simbiosis bintil akarnya, tetapi pembentukan bintil akar itu tidak serta merta terjadi pada waktu tanaman kacang-kacangan itu ditanam. Tanaman kacang merah yang berdaya adaptasi relatif lebih kuat dalam penyerapan unsur hara dibandingkan kacang tanah terlihat memiliki respon terhadap pupuk Urea lebih baik daripada tanaman kacang tanah (Gambar 3).

\section{KESIMPULAN DAN SARAN}

Respon tanaman jagung terhadap pemberian pupuk tunggal $\mathrm{N}, \mathrm{P}$ dan $\mathrm{K}$ serta pupuk majemuk NPK tidak berbeda secara signifikan. Tinggi tanaman dan jumlah daun jagung meningkat secara signifikan seiring umur tanaman, tetapi respon tanaman akibat perlakuan jenis pupuk yang diberikan tidak signifikan berbeda. Berat basah dan berat kering tajuk jagung juga menunjukkan kecenderungan yang sama dalam responnya terhadap jenis pupuk yang diberikan, tetapi perlakuan pupuk tunggal $\mathrm{N}, \mathrm{P}$ dan $\mathrm{K}$ memberikan berat basah dan berat kering tajuk yang relatif lebih tinggi dari perlakuan pupuk lengkap NPK.

Pupuk $\mathrm{N}$ cenderung memberikan pengaruh sukulensi pada tanaman jagung. Penggunaan dosis pupuk yang lebih besar disarankan untuk penelitan respon tanaman selanjutnya. Pemberian air siraman dan perawatan tanaman jagung selama penelitian sangat penting untuk pertumbuhan tanaman.

\section{DAFTAR PUSTAKA}

Effendi, S. 1995. IImu Tanah. Edisi ketiga. PT. Mediyatama Sarana Perkasa. Jakarta.

Gumeleng, G. 2003. Minus One Test Pupuk N, P, dan K Terhadap Pertumbuhan dan Produksi Jagung di Moyag Modayag Kabupaten Bolaang Mongondow. Skripsi. Jurusan Tanah Fakultas Pertanian Universitas Sam Ratulangi, Manado. (tidak dipublikasikan).

Hayati, R.S. 2011. Kesuburan Tanah. Diambil dari http://oryza-sativa135rsh.blogspot.com/ 2011/06/kesuburan-tanah.html pada hari Senin 26 Mei 2015 dan dicek-akses kembali: Jumat 29 April 2016.

Joseph, A. 2011. Peranan Pupuk NPK. Diambil dari http://aldrinjoseph39.blogspot.com/2011/11 /peranan-pupuk-npk 10.html. Diakses: 
Senin 26 Mei 2015 dan dicek-akses kembali: Jumat 29 April 2016.

Juliantoro, M. 2011. Pengaruh Pupuk terhadap Tanaman. Diambil dari http://mohamadjuliantoro.blogspot.com/2011/10/pengaruhpupuk-terhadap-tanaman.html pada hari senin 26 Mei 2015 dan dicek-akses kembali: Jumat 29 April 2016.

Karmana, O. 2006. Faktor yang mempengaruhi pertumbuhan dan perkembangan. Buku Biologi Kelas XII Semester 1 Sekolah Menengah Atas. Diambil dari https://books. google.co.id/books?id=BhMKnV8eHSsC\& $\mathrm{pg}=P R 12 \& \mathrm{dq}=$ tanaman+kacang+merah\&hl =id\&sa=X\&ei=HYpkVdXtEMaWuAT2hlOQ CA\&ved=0CDwQ6AEwBg\#v=onepage\&q= tanaman\%20kacang\%20merah\&f=false pada hari Selasa 02 Juni 2015 dan dicekakses kembali: Jumat 29 April 2016.

Kawulusan, R.I., W.J.N. Kumolontang, L.T. Karamoy, J.N. Luntungan, S.E. Pakasi, dan M. Montolalu. 2015. Respon Pertumbuhan Kacang Tanah Terhadap Pemberian Pupuk-pupuk NPK, Urea, dan SP36. Fakultas Pertanian UNSRAT (tidak dipublikasikan).

Nidayani, F. 2014. Peran Air terhadap pertumbuhan tanaman. Diambil dari https://nidayanif49. wordpress.com/2014/06/16/peran-airterhadap-pertumbuhan-tanaman/ pada hari
Senin 26 Mei 2015 dan dicek-akses kembali: Jumat 29 April 2016.

Purbopuspito, J., T. Titah, Z.E. Tamod, T.Dj. Sondakh, D.D. Pioh, dan J. Husain. 2015. Respon Pertumbuhan Jagung Terhadap Pemberian Pupuk-pupuk NPK, Urea, SP36, dan KCl. Fakultas Pertanian UNSRAT (tidak dipublikasikan).

Rahayu, I. 2012. Manfaat unsur K pada Tanaman. Diambil dari http://indahrahayu7.blogspot. com/2012/09/manfaat-unsur-k-padatanaman.html pada hari jumat 15 Mei 2015 dan dicek-akses kembali: Jumat 29 April 2016.

Rondonuwu, J.J., J.E. Lengkong, J.M.J. Supit, Dj. Kaunang, Y.E.B. Kamagi, dan M.T.M. Sinolungan. 2015. Respon Pertumbuhan Kacang Merah Terhadap Pemberian Pupuk-pupuk NPK, Urea, SP-36, dan KCl. Fakultas Pertanian UNSRAT (tidak dipublikasikan).

Sutejo, M.M. 2002. Pupuk dan Cara Pemupukan. PT. Rineka Cipta, Jakarta.

Tarigan, M. 2010. Tinjauan Pustaka: pupuk dan pemupukan. Universitas Sumatra Utara. Diambil dari http://repository.usu.ac.id/ bitstream/123456789/19718/4/Chapter\%20 II.pdf pada hari Jumat 15 Mei 2015 dan dicek-akses kembali: Jumat 29 April 2016. 


\section{LAMPIRAN-LAMPIRAN}

Tabel Lampiran 1. Jumlah Daun Tanaman Jagung (Zea mays, L.) Rata-rata (helai) Selama Percobaan

(Appendix Table 1. Average Number of Maize (Zea mays, L.) Leaves During Experiment)

\begin{tabular}{ccccccc}
\hline Tanggal & umur & \multicolumn{5}{c}{ Jumlah daun tanaman rata-rata (helai) pada perlakuan pupuk: } \\
\cline { 3 - 7 } pengamatan & (MST) & Tanpa pupuk & NPK & N & P & K \\
\hline $27 / 02 / 15$ & 0 & 0 & 0 & 0 & 0 & 0 \\
$06 / 03 / 15$ & 1 & 2 & 1 & 2 & 2 & 2 \\
$13 / 03 / 15$ & 2 & 4 & 3 & 4 & 3 & 3 \\
$20 / 03 / 15$ & 3 & 3 & 4 & 4 & 3 & 4 \\
$27 / 03 / 15$ & 4 & 5 & 4 & 5 & 5 & 4 \\
$03 / 04 / 15$ & 5 & 6 & 5 & 6 & 6 & 7 \\
$10 / 04 / 15$ & 6 & 5 & 5 & 5 & 4 & 6 \\
$17 / 04 / 15$ & 7 & 5 & 5 & 5 & 4 & 8 \\
$24 / 04 / 15$ & 8 & 6 & 6 & 6 & 5 & 8 \\
\hline
\end{tabular}

Tabel Lampiran 2. Berat Basah dan Berat Kering Tajuk Tanaman Jagung (Zea mays, L.)

(Appendix Table 2. Average Fresh and Dry Weight of Maize (Zea mays, L.) stalks)

\begin{tabular}{cccccc}
\hline \multirow{2}{*}{$\begin{array}{c}\text { Ulangan } \\
\text { perlakuan }\end{array}$} & \multicolumn{5}{c}{ Berat tajuk tanaman Jagung pada perlakuan pupuk: } \\
\cline { 2 - 6 } & Tanpa pupuk & NPK & N & P & $\mathrm{K}$ \\
\hline & & & Berat basah (g) & \\
2 & 8,5 & 14,8 & 17,5 & 7,5 & \\
3 & 11,2 & 11,6 & 9,1 & 14,3 & 22,2 \\
4 & 21,5 & 26,7 & 25,6 & & \\
5 & 40,1 & 24,0 & 28,0 & 28,0 & \\
6 & 39,4 & 35,5 & 74,3 & 81,3 & \\
& 20,9 & 21,7 & 25,6 & 16,5 & \\
1 & 1,0 & & Berat kering (g) & & \\
2 & 1,9 & 0,5 & 2,0 & 2,0 & \\
3 & 3,3 & 4,8 & 1,4 & 1,8 & \\
4 & 4,1 & 3,3 & 3,5 & & \\
5 & 6,0 & 4,0 & 3,0 & 3,0 & \\
6 & 3,5 & 3,0 & 10,5 & 10,0 & \\
\hline
\end{tabular}



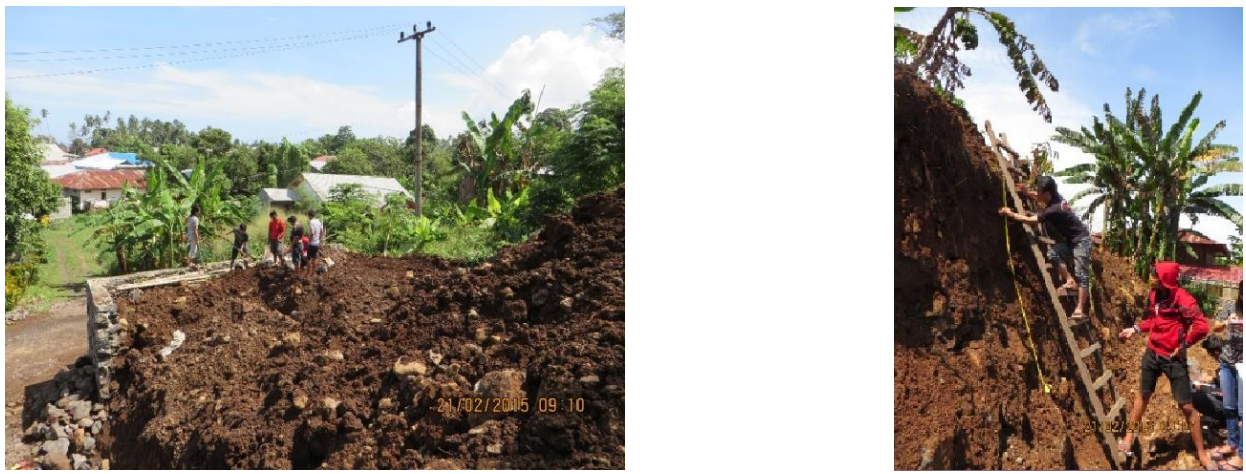

Gambar Lampiran 1. Pengambilan Sampel Tanah untuk Percobaan Pot (Appendix Figure 1. Taking Soil Sample for Potted Trials)
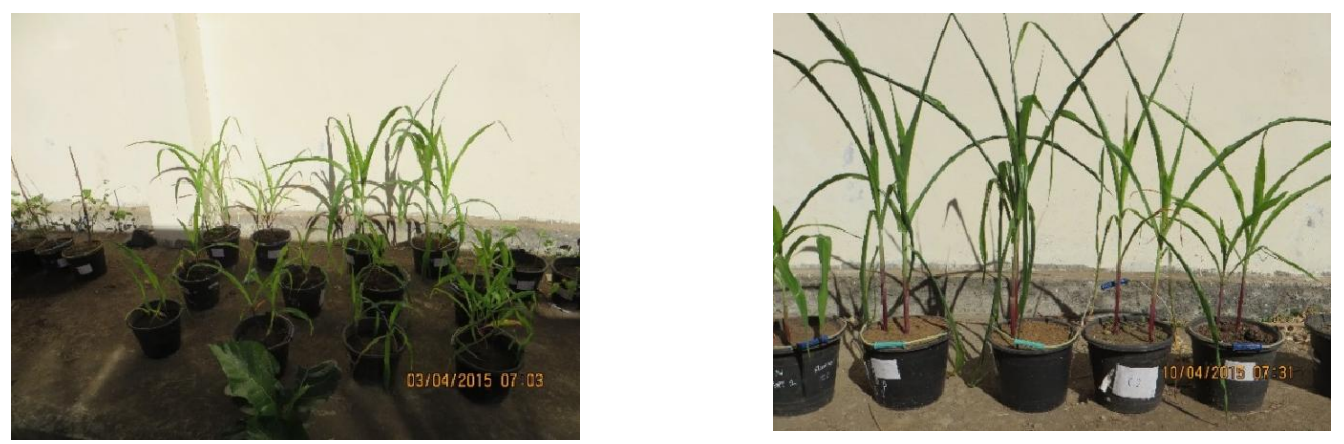

Gambar Lampiran 2. Tanaman Jagung (Zea mays, L.) Berumur 4 dan 5 MST (Appendix Figure 2. Maize (Zea mays, L.) Plants of 4 and 5 WAP old) 